\title{
The independent relationship between triglycerides and coronary heart disease
}

\author{
Alan Morrison' \\ John E Hokanson² \\ 'SCRIBCO, Blue Bell, PA, USA; \\ ${ }^{2}$ Department of Epidemiology, \\ Colorado School of Public Health, \\ University of Colorado at Denver \\ Denver, CO, USA
}

\begin{abstract}
Aims: The aim was to review epidemiologic studies to reassess whether serum levels of triglycerides should be considered independently of high-density lipoprotein-cholesterol (HDL-C) as a predictor of coronary heart disease (CHD).

Methods and results: We systematically reviewed population-based cohort studies in which baseline serum levels of triglycerides and HDL-C were included as explanatory variables in multivariate analyses with the development of CHD (coronary events or coronary death) as dependent variable. A total of 32 unique reports describing 38 cohorts were included. The independent association between elevated triglycerides and risk of CHD was statistically significant in 16 of 30 populations without pre-existing CHD. Among populations with diabetes mellitus or pre-existing CHD, or the elderly, triglycerides were not significantly independently associated with CHD in any of 8 cohorts. Triglycerides and HDL-C were mutually exclusive predictors of coronary events in 12 of 20 analyses of patients without pre-existing CHD.

Conclusions: Epidemiologic studies provide evidence of an association between triglycerides and the development of primary CHD independently of HDL-C. Evidence of an inverse relationship between triglycerides and HDL-C suggests that both should be considered in CHD risk estimation and as targets for intervention.
\end{abstract}

Keywords: coronary heart disease, triglycerides, high-density lipoprotein-cholesterol, low-density lipoprotein-cholesterol, hypercholesterolemia

\section{Introduction}

Serum cholesterol levels are important components of guidelines for determining risk and treatment of coronary heart disease (CHD). Low-density lipoprotein-cholesterol (LDL-C), the primary component of total cholesterol, is recognized as the most important lipid risk factor. Cardiovascular risk assessment in US and UK guidelines is based on the Framingham algorithm, in which the 10-year risk of CHD is calculated from levels of total cholesterol and high-density lipoprotein-cholesterol (HDL-C), and from demographic and clinical factors. ${ }^{1,2}$ Serum triglyceride levels are not a factor in quantifying CHD risk in these guidelines. A different basis for cardiovascular risk assessment has been adopted by the joint European societies. ${ }^{3}$ European guidelines base their treatment recommendations on the ten-year risk of coronary death, which is calculated from the plasma level of total cholesterol and nonlipid risk factors. ${ }^{4,5}$ Both the UK and European guidelines, however, recognize that elevated triglycerides increase the risk of CHD. ${ }^{5-7}$

Triglycerides do appear in international guidelines in considering therapy. Hypertriglyceridemia is recognized as a therapeutic target in UK guidelines. In European and US guidelines, combined elevated triglycerides and low HDL-C are to be considered when deciding on therapy.

The position of triglycerides in the guidelines is largely secondary to that of HDL-C. Given that the relationship between triglycerides and CHD is based on 
epidemiological studies, the objective here was to review the literature describing those studies to reassess whether triglycerides should be considered independently of HDL-C as a predictor of CHD and target for treatment.

\section{Methods}

Articles describing population-based cohort studies were identified in a February 2008 update of searches described in published meta-analyses. ${ }^{8-10}$ Articles were included in this literature review if they met the following criteria: cohort study of risk of cardiovascular disease; measurement of triglycerides at baseline; a multiple regression analysis of the independent association between triglycerides and risk of CHD, with HDL-C as an explanatory variable; article published in the peer-reviewed literature; and article in English. A total of 46 articles met these inclusion criteria. ${ }^{11-56}$ To avoid double counting, we considered only one analysis of any cohort (except for subpopulations) - typically the most recent publication meeting the inclusion criteria. Multiple articles reporting the Copenhagen Male Study (CMS) ${ }^{28-30}$ Caerphilly and Speedwell Collaborative Heart Disease Studies (CSCHDS), ${ }^{15,52}$ Framingham Heart Study (FHS; for men but not women), ${ }^{20,51}$ Prospective Cardiovascular Münster Study (PROCAM), ${ }^{12-14}$ Lipid Research Clinics Prevalence and Mortality Follow-Up Study (LRC-FS), ${ }^{11,19}$ Nurses' Health Study (NHS), ${ }^{43,44}$ and occupational groups examined in Rome (ROG) $)^{35,36}$ cohorts typically agreed on the study result (significance of the association between triglycerides and CHD) or reached a consensus. Two reports of the Multiple Risk Factor Intervention Trial (MRFIT) study disagreed, however: the 25-year follow-up analysis reported a significant association, whereas a 6.1-year follow-up did not (the article reporting the 25-year follow-up was used for the MRFIT study). ${ }^{11,22}$ After excluding duplicate reports of the same cohort, a report in which the outcome was all-cause deaths, ${ }^{24}$ and a report in which the outcome was heart failure, ${ }^{26} 32$ reports with coronary events or coronary death as outcome remained and were included in the analysis. ${ }^{11,14,18,20-23,25,27,30-32,34,36-50,52,54-56}$ As some articles described more than one cohort, ${ }^{11}$ more than one subpopulation of a cohort (eg, men and women separately), and we included only one outcome measure per cohort (coronary events only, if coronary deaths were also reported), results for a total of 38 different populations were included in the analysis. These populations were categorized as patients without pre-existing CHD or as "high risk populations" - defined as patients with diabetes, pre-existing CHD, or the elderly - and into men or women or men/women within these categories.
The cohorts included were: among populations without pre-existing CHD, 17 for men (Atherosclerosis Risk in Communities study [ARIC],${ }^{45}$ Canadian Community Health Survey [CCHS], ${ }^{54} \mathrm{CMS},{ }^{30} \mathrm{CSCHDS},{ }^{52} \mathrm{CUORE},{ }^{23} \mathrm{FHS},{ }^{20}$ Göttingen Risk, Incidence and Prevalence Study [GRIPS],$^{18}$ Health Professional's Follow-Up Study [HPFUS], ${ }^{40}$ Lipid Research Clinics Coronary Primary Prevention Trial [LRC-CPPT] ${ }^{11}$ Metabolic, Lifestyle, and Nutrition Assessment in Young Adults [MELANY] ${ }^{55}$ MRFIT, ${ }^{22}$ the second Northwick Park Heart Study [NPHSII], ${ }^{48}$ Physician's Health Study [PHS], ${ }^{46}$ PROCAM,,${ }^{14}$ Quebec Cardiovascular Study [QCVS], ${ }^{39}$ Uppsala Longitudinal Study of Adult Men $[\mathrm{ULSAM}],{ }^{21}$ Western Collaborative Group Study [WCGS ${ }^{25}$ ), 2 for men/women (4CJ, ${ }^{27}$ Asia Pacific Cohort Studies Collaboration $[\mathrm{APCSC}]^{38}$ ), and 5 for women (ARIC, ${ }^{45} \mathrm{CCHS},{ }^{54}$ FHS,${ }^{20}$ NHS,${ }^{44}$ Women's Health Study $[\text { WHS }]^{56}$ ) with coronary events as outcome, and 3 for men (Apolipoprotein Mortality Risk Study [AMORIS], ${ }^{50}$ LRC-FS, ${ }^{11} \mathrm{ROG}^{36}$ ) and 3 for women (AMORIS, ${ }^{50}$ Enlarged Waist with Elevated Triglycerides study [EWET] ${ }^{49}$ LRC-FS ${ }^{11}$ ) with coronary deaths as outcome; among high risk populations with coronary events as outcome, 1 with diabetes (Kuopio ${ }^{32}$ ), 5 with diabetes without pre-existing CHD (HPFUS, ${ }^{31}$ ARIC, ${ }^{42}$ SHS,${ }^{34}$ UKPDS, $\left.{ }^{47} \mathrm{NHS}^{43}\right), 1$ of the elderly without prior MI $\left(\mathrm{CHS}^{41}\right)$ or stroke, and 1 post-MI (THROMBO $\left.{ }^{37}\right)$.

The primary outcome measure was a multivariate estimate of the statistical significance of the independent association between triglycerides and CHD, with HDL-C and other lipids (LDL-C, triglycerides, etc.) as explanatory variables. A secondary outcome measure was a univariate analysis of the statistical significance of the association between triglycerides and CHD, typically based on an ANOVA comparison of triglyceride concentrations in patients who did and did not subsequently experience CHD. CHD was classified as coronary events and coronary deaths. Outcomes described by authors as myocardial infarction (MI), CHD, or ischemic heart disease, were reclassified as coronary events.

Examination of the articles indicated that no consistent definition of the independent variable (triglyceride concentration) was applied and, in most reports of multivariate models of the association between triglycerides and CHD, a $\mathrm{P}$ value was the only information provided, frequently as $\mathrm{P}<0.05$ or nonsignificant (NS) $(\mathrm{P}>0.05)$. Therefore, a descriptive approach was taken: we enumerated the number of cohorts in which triglycerides were or were not a significant independent predictor of CHD. We also summarized results by various study characteristics - the study population, study 
size (patient-years of follow-up), fasting status of patients at baseline lipid measurement, the type of multivariate model (proportional hazards models or unconditional multiple logistic regression), the definition of the independent variable (triglyceride concentration), and lipid variables included in the model. We took the median point for these variables and simply enumerated the number of cohorts above and below the median in which triglycerides were independently associated with the development of CHD. The number of patient-years of follow-up was as reported in the original articles or, if not cited, was calculated from the number of patients and the average years of follow-up; if the average years of follow-up was not reported, the study duration was used.

\section{Results}

\section{Consistent association between triglycerides and CHD in univariate analyses}

In univariate analyses of patients without pre-existing CHD, the plasma triglyceride concentration was significantly associated with CHD in 16 of 16 cohorts with coronary events as outcome $11,18,21,22,25,27,30,39,40,44-46,48,52,56$ and in 6 of 6 cohorts with coronary death as outcome. ${ }^{11,36,49,50}$ This was also the case in 5 of 5 studies of diabetic patients with coronary events as outcome..$^{31,32,34,42,43}$ In only one study, in which patients had a prior MI, were triglycerides not significantly associated with recurrent coronary events. ${ }^{37}$ Representative relative risks (RRs) of coronary events, adjusted for matching demographic and other nonlipid factors, were RR 2.41 (95\% CI 1.43-4.07) for men in the HPFUS cohort and 3.5 (1.8-7.3) for women in the NHS cohort (RR comparing the top and bottom quintiles of triglyceride levels). ${ }^{40,44}$

\section{Inconsistent association between triglycerides and CHD in multivariate models including HDL-C}

The pertinent results of multivariate analyses in which triglycerides, HDL-C, and other lipids were entered as independent variables are summarized in Table 1. The relationship between triglycerides and subsequent coronary events or coronary death was statistically significant in 16 instances ${ }^{14,20,22,27,30,38,45,46,48-50,52,54-56}$ (CCHS, ${ }^{54} \mathrm{CMS},{ }^{30}$ CSCHDS, ${ }^{52}$ MELANY,${ }^{55}$ MRFIT, ${ }^{22}$ NPHSII, ${ }^{48} \mathrm{PHS},{ }^{46}$ and PROCAM ${ }^{14}$ for men; $4 \mathrm{CJ}^{27}$ and $\mathrm{APCSC}^{38}$ for men/women; and ARIC, ${ }^{45}$ AMORIS $,{ }^{50} \mathrm{CCHS},{ }^{54} \mathrm{FHS},{ }^{20} \mathrm{EWET},{ }^{49}$ and $\mathrm{WHS}^{56}$ for women) and not significant in 14 instances ${ }^{11,1}$ 8,20,21,23,25,36,39,40,44,45,50 (ARIC, ${ }^{45}$ CUORE, ${ }^{23}$ FHS, ${ }^{20}$ GRIPS, ${ }^{18}$ HPFUS, ${ }^{40}$ LRC-CPPT, ${ }^{11}$ QCVS, ${ }^{39} \mathrm{ULSAM}^{21}$ WCGS,${ }^{25}$

Table I Numbers of cohorts in which triglycerides were or were not predictive of CHD independently of HDL-C, by selected study characteristics

\begin{tabular}{|c|c|c|c|c|}
\hline \multirow[t]{2}{*}{ Characteristic } & \multirow[t]{2}{*}{ Outcome variable } & \multicolumn{3}{|c|}{ Number of cohorts } \\
\hline & & $\begin{array}{l}\text { Triglycerides } \\
\text { significant }\end{array}$ & $\begin{array}{l}\text { Triglycerides not } \\
\text { significant }\end{array}$ & Total \\
\hline All studies & $\mathrm{CHD}$ & 16 & 22 & 38 \\
\hline High-risk populations & Coronary events & 0 & 8 & 8 \\
\hline \multicolumn{5}{|l|}{ Primary populations } \\
\hline All & $\mathrm{CHD}$ & 16 & 14 & 30 \\
\hline \multicolumn{5}{|l|}{ Sex } \\
\hline Women & $\mathrm{CHD}$ & 6 & 2 & 8 \\
\hline Women/men & $\mathrm{CHD}$ & 2 & 0 & 2 \\
\hline Men & $\mathrm{CHD}$ & 8 & 12 & 20 \\
\hline \multicolumn{5}{|l|}{ Outcome variable } \\
\hline Coronary death & Coronary deaths & 2 & 4 & 6 \\
\hline Coronary events & Coronary events & 14 & 10 & 24 \\
\hline \multicolumn{5}{|l|}{ Cohort size } \\
\hline$<52,000$ patient-years & Coronary events & 6 & 6 & 12 \\
\hline$>52,000$ patient-years & Coronary events & 8 & 4 & 12 \\
\hline \multicolumn{5}{|l|}{ Triglyceride measurement } \\
\hline Fasting & Coronary events & 9 & 10 & 19 \\
\hline Nonfasting & Coronary events & 6 & 0 & 6 \\
\hline
\end{tabular}

Abbreviations: CHD, coronary heart disease (defined as either coronary events or coronary death). 
AMORIS, ${ }^{50}$ LRC-FS, ${ }^{11}$ and $\mathrm{ROG}^{36}$ for men; and $\mathrm{NHS}^{44}$ and LRC-FS ${ }^{11}$ for women) in analyses of populations without pre-existing CHD. In studies of high risk populations, the relationship between triglycerides and subsequent coronary events was not statistically significant in any of the 8 cohorts. $^{31,32,34,37,41-43,47}$

Although inconclusive, there is some indication that the association between triglycerides and CHD may be more frequently detectable among women and among populations without pre-existing CHD. Among populations without pre-existing $\mathrm{CHD}$, triglycerides were significantly associated with CHD in 6 of 8 analyses of women, ${ }^{20,45,49,50,54,56}$ 2 of 2 analyses of men/women, ${ }^{27,38}$ and 8 of 20 analyses of men. ${ }^{14,22,30,46,48,52,54,55}$ As indicated, the relationship between triglycerides and coronary events was significant in none of 8 high risk populations.

The association between triglyceride levels and subsequent coronary events was not correlated with cohort size in populations without pre-existing CHD. In 12 cohorts of between 6,835 and 50,848 patient-years, the association was significant in 6 cohorts; in 12 cohorts of 53,890 to 796,671 patient-years, the association between triglyceride levels and subsequent coronary events was significant in 8 (cohorts not listed).

In an analysis of the WHS, Bansal and colleagues recently argued that nonfasting but not fasting triglyceride levels were independently associated with cardiovascular events (fasting triglycerides were significantly predictive of coronary events when the proportional hazards model included as covariates age, blood pressure, smoking status, use of hormone replacement therapy, triglycerides, and HDL-C, but not when diabetes mellitus, body mass index, and high-sensitivity C-reactive protein were also added). ${ }^{56}$ Referring to participants without pre-existing CHD, we observed that triglycerides were a significant independent predictor of coronary events in 6 of 6 populations with nonfasting blood samples $27,46,48,54,56$ and 9 of 19 instances with fasting blood samples ${ }^{14,20,22,30,38,45,49,52,55}$ (Patients in all analyses of high risk populations provided fasting blood samples).

Details of the multivariate modeling did not appear to affect whether triglycerides were significant. Both significant and nonsignificant associations between triglycerides and coronary events occurred in both proportional hazards models ( 9 significant ${ }^{14,22,27,38,48,54-56}$ and 3 nonsignificant ${ }^{11,21,23}$ ) and multiple logistic regression models ( 3 significant $^{30,46,52}$ and 5 nonsignificant ${ }^{18,25,39,40,44}$ ). The independent variable (triglyceride concentration) was entered into some models as a continuous variable, sometimes log-transformed; in other cases, triglyceride concentration was treated as a categorical variable, and divided into tertiles, quartiles, or quintiles. However, the definition of the triglyceride variable did not appear to affect whether triglycerides were significant (cohorts not listed). We also considered the lipid and nonlipid variables that were included in the models, but none of these factors appeared to vary systematically by triglyceride result. LDL-C, for example, was a significant independent variable in 10 studies with coronary events as dependent variable, among which triglycerides were significant in $4^{14,22,30,48}$ and nonsignificant in $6 .{ }^{11,18,39,40,44,57}$ In 6 other studies, in which total cholesterol was significant, triglycerides were significant in $4^{27,46,48,52}$ and nonsignificant in $2 .^{23,25}$ And in 3 studies in which apolipoprotein B was significant, triglycerides were significant in $1^{48}$ and nonsignificant in $2 .{ }^{40,57}$

\section{Discussion}

Statistically significant and quite strong negative correlations between triglycerides and HDL-C were reported in some of the cohorts analyzed, with values ranging from -0.26 to $-0.58 .^{32,38,40,44,46,51,52,56,58,59}$ Given this negative correlation, we considered whether triglycerides and HDL-C were mutually exclusive predictors of CHD. That is, we considered whether HDL-C and triglycerides were identified in the same multivariate model as independent predictors of coronary events. Of 20 analyses with coronary events as outcome for patients without pre-existing CHD, there were 6 instances in which HDL-C was a significant independent predictor of CHD but triglycerides were not, and 6 instances in which triglycerides were significant but HDL-C was not. There were 4 instances in which both triglycerides and HDL-C were significant independent predictors of CHD and 4 instances in which neither was significant. This suggests that a negative correlation between triglycerides and HDL-C may have obscured the relationship between triglyceride levels and risk of CHD.

Previously, investigators have taken a meta-analytic approach to determine whether triglycerides are significantly predictive of CHD independently of HDL-C. ${ }^{8-10,60}$ Beginning in $1996,{ }^{8}$ these authors concluded that triglycerides were a risk factor for cardiovascular disease in the general population, independently of HDL-C. A pooled, multivariable-adjusted $\mathrm{RR}$, with respect to a $1 \mathrm{mmol} / \mathrm{L}$ increase in serum triglycerides, was reported as RR 1.14 (95\% CI 1.05-1.28) for six studies of men and RR 1.37 (95\% CI 1.13-1.66) for two of studies of women. ${ }^{8}$ The most recent (2007) pooled analysis included 11 articles reporting multivariable adjustment for HDLC. ${ }^{60}$ 
The meta-analytic approach, however, is limited by a dependence on reporting in the literature of data in a form suitable for statistical pooling. Given the variety of analytic approaches taken in the primary studies, statistical pooling across all studies depends on a process of assumption, inference, and imputation. ${ }^{61}$ In contrast, our descriptive approach did not require any particular data reporting format and allowed analysis of a much larger data set of 32 articles reporting 38 cohorts.

The epidemiological data in the current analysis provide support for triglycerides as a predictor of CHD independently of HDL-C, but possibly only in certain categories of patient or level of CHD risk. Triglycerides were not independently predictive of CHD in 8 of 8 high risk cohorts, perhaps because the association between triglycerides and CHD is relatively weak and is outweighed by other factors in high-risk populations. Triglycerides were predictive of CHD independently of HDL-C in about half of the lower risk, primary cohorts. This may reflect random error and a relatively weak association that might fall on either side of the cut-point of $\mathrm{P}=0.05$ (The disadvantage of our descriptive approach is that it does not account for the numerical strength of an association, but simply whether it falls on either side of a cut-point). Consistent with these arguments, triglycerides were most often (in 6 of 8 cohorts) independently predictive of CHD in the lower-risk, primary populations of women.

The data also point to the inverse correlation of triglycerides and HDL-C in their role as risk factors. The inverse relationship between triglyceride and HDL-C levels likely reflects their respective participation in lipid transport and reverse cholesterol transport. The inverse relationship holds in the effects of lipid-modifying drugs. Niacin, ${ }^{62}$ fibrates, ${ }^{62}$ statins, ${ }^{63,64}$ CETP inhibitors, ${ }^{65}$ and gemcabene ${ }^{66}$ all concomitantly increase HDL-C and decrease triglyceride levels. Certain genetic changes also have inverse effects on HDL-C and triglycerides. Mutations in ABCA1, a gene encoding a protein involved in cholesterol transport, result in lowered HDL-C and raised triglycerides levels, in conjunction with an increased risk of CHD. ${ }^{67}$ Similarly, a mutation in the gene encoding lipoprotein lipase, and causing a lipoprotein lipase deficiency, decreases HDL-C levels, while increasing triglycerides levels and the risk of CHD. ${ }^{68-71}$ The opposite effects are seen with a mutation in the lipoprotein lipase gene that results in increased enzyme activity: HDL-C is increased, while triglyceride levels and the risk of CHD are decreased. ${ }^{72,73}$ The inverse relationship does not seem to be absolute, however, since other genetic alterations indicate that the inverse relationship between HDL-C and triglyceride levels can be uncoupled. Subjects with an inherited hepatic lipase deficiency have hypertriglyceridemia in combination with increased HDL-C, associated with premature atherosclerosis and increased risk of CHD. ${ }^{74-78}$ This suggests that the cardio-protective effect of elevated HDL-C is not seen in the absence of the inverse relationship with triglycerides.

\section{Conclusions}

Epidemiological evidence indicates that plasma triglyceride levels are predictive of CHD. The relationship between triglycerides and CHD is stronger and more consistently observed in populations without elevated CHD risk (eg, without pre-existing CHD). Population based screening for elevated triglycerides may identify individuals at elevated risk for CHD who may not otherwise be detected. Multivariate analyses indicate that the strong inverse relationship between triglycerides and HDL-C may reflect a common pathophysiologic process. This suggests that high triglycerides or low HDL-C or both might be considered for use in CHD risk estimation and that both triglycerides and HDL-C may be considered targets for therapeutic or lifestyle interventions.

\section{Acknowledgments}

The authors are grateful to Vasilisa Sazonov, $\mathrm{PhD}$ for inspiring this work, to Samantha Soldan, $\mathrm{PhD}$ and Victoria Stern for research and medical writing assistance, and to Baishali $\mathrm{M}$. Ambegaonkar for helpful comments on the manuscript.

\section{Disclosure}

Merck and Co., Inc. provided funding for this study.

\section{References}

1. Expert Panel on Detection, Evaluation, and Treatment of High Blood Cholesterol in Adults. Executive Summary of the Third Report of the National Cholesterol Education Program (NCEP) Expert Panel on Detection, Evaluation, and Treatment of High Blood Cholesterol in Adults (Adult Treatment Panel III). JAMA. 2001;285:2486-97.

2. British Cardiac Society, British Hypertension Society, Diabetes UK, et al. JBS 2: Joint British Societies' guidelines on prevention of cardiovascular disease in clinical practice. Heart. 2005;91(Suppl 5):v1-52.

3. Conroy RM, Pyorala K, Fitzgerald AP, et al. Estimation of ten-year risk of fatal cardiovascular disease in Europe: the SCORE project. Eur Heart J. 2003;24:987-1003.

4. Prevention of coronary heart disease in clinical practice. Recommendations of the Second Joint Task Force of European and other Societies on coronary prevention. Eur Heart J. 1998;19:1434-503.

5. De Backer G, Ambrosioni E, Borch-Johnsen K, et al. European guidelines on cardiovascular disease prevention in clinical practice. Third Joint Task Force of European and Other Societies on Cardiovascular Disease Prevention in Clinical Practice. Eur Heart J. 2003;24:1601-10.

6. Wood DA, Durrington P, McInnes G, et al. Joint British recommendations on prevention of coronary heart disease in clinical practice. Heart. 1998;80(Suppl):S1-29. 
7. Joint British recommendations on prevention of coronary heart disease in clinical practice: summary. British Cardiac Society, British Hyperlipidaemia Association, British Hypertension Society, British Diabetic Association. BMJ. 2000;320:705-8.

8. Hokanson JE, Austin MA. Plasma triglyceride level is a risk factor for cardiovascular disease independent of high-density lipoprotein cholesterol level: a meta-analysis of population-based prospective studies. J Cardiovasc Risk. 1996;3:213-19.

9. Austin MA, Hokanson JE, Edwards KL. Hypertriglyceridemia as a cardiovascular risk factor. Am J Cardiol. 1998;81(4A):7B-2B.

10. Abdel-Maksoud MF, Hokanson JE. The complex role of triglycerides in cardiovascular disease. Semin Vasc Med. 2002;2:325-33.

11. Avins AL, Neuhaus JM. Do triglycerides provide meaningful information about heart disease risk? Arch Intern Med. 2000;160:1937-44.

12. Assmann G, Schulte H. Relation of high-density lipoprotein cholesterol and triglycerides to incidence of atherosclerotic coronary artery disease (the PROCAM experience). Prospective Cardiovascular Munster study. Am J Cardiol. 1992;70:733-7.

13. Assmann G, Schulte H, von Eckardstein A. Hypertriglyceridemia and elevated lipoprotein(a) are risk factors for major coronary events in middle-aged men. Am J Cardiol. 1996;77:1179-84.

14. Assmann G, Cullen P, Schulte H. Simple scoring scheme for calculating the risk of acute coronary events based on the 10-year follow-up of the prospective cardiovascular Munster (PROCAM) study. Circulation. 2002;105:310-15.

15. Bainton D, Miller NE, Bolton CH, et al. Plasma triglyceride and high density lipoprotein cholesterol as predictors of ischaemic heart disease in British men. The Caerphilly and Speedwell Collaborative Heart Disease Studies. Br Heart J. 1992;68:60-6.

16. Bos G, Dekker JM, Nijpels G, et al;Hoorn Study. A combination of high concentrations of serum triglyceride and non-high-density-lipoprotein-cholesterol is a risk factor for cardiovascular disease in subjects with abnormal glucose metabolism - The Hoorn Study. Diabetologia. 2003;46:910-16.

17. Burchfiel CM, Laws A, Benfante R, et al. Combined effects of HDL cholesterol, triglyceride, and total cholesterol concentrations on 18-year risk of atherosclerotic disease. Circulation. 1995;92:1430-6.

18. Cremer P, Nagel D, Mann H, et al. Ten-year follow-up results from the Goettingen Risk, Incidence and Prevalence Study (GRIPS). I. Risk factors for myocardial infarction in a cohort of $5790 \mathrm{men}$. Atherosclerosis. 1997; 129:221-30

19. Criqui MH, Heiss G, Cohn R, et al. Plasma triglyceride level and mortality from coronary heart disease. $N$ Engl J Med. 1993;328:1220-5.

20. D'Agostino RB, Russell MW, Huse DM, et al. Primary and subsequent coronary risk appraisal: new results from the Framingham study. Am Heart J. 2000;139(2 Pt 1):272-81.

21. Dunder K, Lind L, Lagerqvist B, et al. Cardiovascular risk factors for stable angina pectoris versus unheralded myocardial infarction. $\mathrm{Am}$ Heart J. 2004;147:502-8.

22. Eberly LE, Stamler J, Neaton JD. Relation of triglyceride levels, fasting and nonfasting, to fatal and nonfatal coronary heart disease. Arch Intern Med. 2003;163:1077-83.

23. Ferrario M, Chiodini P, Chambless LE, et al. Prediction of coronary events in a low incidence population. Assessing accuracy of the CUORE Cohort Study prediction equation. Int J Epidemiol. 2005;34:413-21.

24. Haim M, Benderly M, Brunner D, et al. Elevated serum triglyceride levels and long-term mortality in patients with coronary heart disease: the Bezafibrate Infarction Prevention (BIP) Registry. Circulation. 1999; 100:475-82.

25. Hulley SB, Rosenman RH, Bawol RD, et al. Epidemiology as a guide to clinical decisions. The association between triglyceride and coronary heart disease. $N$ Engl J Med. 1980;302:1383-9.

26. Ingelsson E, Arnlov J, Sundstrom J, et al. Novel metabolic risk factors for heart failure. J Am Coll Cardiol. 2005;46:2054-60.

27. Iso H, Naito $\mathrm{Y}$, Sato $\mathrm{S}$, et al. Serum triglycerides and risk of coronary heart disease among Japanese men and women. Am J Epidemiol. 2001;153:490-9.
28. Jeppesen J, Hein HO, Suadicani P, et al. Relation of high TG-low HDL cholesterol and LDL cholesterol to the incidence of ischemic heart disease. An 8-year follow-up in the Copenhagen Male Study. Arterioscler Thromb Vasc Biol. 1997;17:1114-20.

29. Jeppesen J, Hein HO, Suadicani P, et al. Triglyceride concentration and ischemic heart disease: an eight-year follow-up in the Copenhagen Male Study. Circulation. 1998;97:1029-36.

30. Jeppesen J, Hein HO, Suadicani P, et al. Low triglycerides-high highdensity lipoprotein cholesterol and risk of ischemic heart disease. Arch Intern Med. 2001;161:361-6.

31. Jiang R, Schulze MB, Li T, et al. Non-HDL cholesterol and apolipoprotein $\mathrm{B}$ predict cardiovascular disease events among men with type 2 diabetes. Diabetes Care. 2004;27:1991-7.

32. Laasko M, Lehto S, Penttla I, et al. Lipids and lipoproteins predicting coronary heart disease mortality and morbidity in patients with noninsulin-dependent diabetes. Circulation. 1993;88(4 Pt 1):1421-30.

33. Lehto S, Ronnemaa T, Haffner SM, et al. Dyslipidemia and hyperglycemia predict coronary heart disease events in middle-aged patients with NIDDM. Diabetes. 1997;46:1354-9.

34. Lu W, Resnick HE, Jablonski KA, et al. Non-HDL cholesterol as a predictor of cardiovascular disease in type 2 diabetes: the strong heart study. Diabetes Care. 2003;26:16-23.

35. Menotti A, Spagnolo A, Scanga M, et al. Multivariate prediction of coronary deaths in a 10 year follow-up of an Italian occupational male cohort. Acta Cardiol. 1992;47:311-20.

36. Menotti A, Scanga M, Morisi G. Serum triglycerides in the prediction of coronary artery disease (an Italian experience). Am J Cardiol. 1994;73:29-32.

37. Moss AJ, Goldstein RE, Marder VJ, et al. Thrombogenic factors and recurrent coronary events. Circulation. 1999;99:2517-22.

38. Patel A, Barzi F, Jamrozik K, et al. Serum triglycerides as a risk factor for cardiovascular diseases in the Asia-Pacific region. Circulation. 2004;110:2678-86.

39. Pirro M, Mauriege P, Tchernof A, et al. Plasma free fatty acid levels and the risk of ischemic heart disease in men: prospective results from the Quebec Cardiovascular Study. Atherosclerosis. 2002;160:377-84.

40. Pischon T, Girman CJ, Sacks FM, et al. Non-high-density lipoprotein cholesterol and apolipoprotein $\mathrm{B}$ in the prediction of coronary heart disease in men. Circulation. 2005;112:3375-83.

41. Psaty BM, Anderson M, Kronmal RA, et al. The association between lipid levels and the risks of incident myocardial infarction, stroke, and total mortality: The Cardiovascular Health Study. J Am Geriatr Soc. 2004;52:1639-47.

42. Saito I, Folsom AR, Brancati FL, et al. Nontraditional risk factors for coronary heart disease incidence among persons with diabetes: the Atherosclerosis Risk in Communities (ARIC) Study. Ann Intern Med. 2000;133:81-91.

43. Schulze MB, Shai I, Manson JE, et al. Joint role of non-HDL cholesterol and glycated haemoglobin in predicting future coronary heart disease events among women with type 2 diabetes. Diabetologia. 2004;47:2129-36.

44. Shai I, Rimm EB, Hankinson SE, et al. Multivariate assessment of lipid parameters as predictors of coronary heart disease among postmenopausal women: potential implications for clinical guidelines. Circulation. 2004;110:2824-30.

45. Sharrett AR, Ballantyne CM, Coady SA, et al. Coronary heart disease prediction from lipoprotein cholesterol levels, triglycerides, lipoprotein(a), apolipoproteins A-I and B, and HDL density subfractions: The Atherosclerosis Risk in Communities (ARIC) Study. Circulation. 2001;104:1108-13.

46. Stampfer MJ, Krauss RM, Ma J, et al. A prospective study of triglyceride level, low-density lipoprotein particle diameter, and risk of myocardial infarction. JAMA. 1996;276:882-8.

47. Stevens RJ, Kothari V, Adler AI, et al. The UKPDS risk engine: a model for the risk of coronary heart disease in Type II diabetes (UKPDS 56). Clin Sci (Lond). 2001;101:671-9. 
48. Talmud PJ, Hawe E, Miller GJ, et al. Nonfasting apolipoprotein B and triglyceride levels as a useful predictor of coronary heart disease risk in middle-aged UK men. Arterioscler Thromb Vasc Biol. 2002;22:1918-23.

49. Tanko LB, Bagger YZ, Qin G, et al. Enlarged waist combined with elevated triglycerides is a strong predictor of accelerated atherogenesis and related cardiovascular mortality in postmenopausal women. Circulation. 2005;111:1883-90.

50. Walldius G, Jungner I, Holme I, et al. High apolipoprotein B, low apolipoprotein A-I, and improvement in the prediction of fatal myocardial infarction (AMORIS study): a prospective study. Lancet. 2001;358:2026-33.

51. Wilson PW, Larson MG, Castelli WP. Triglycerides, HDL cholesterol and coronary artery disease: a Framingham update on their interrelations. Can J Cardiol. 1994;10(Suppl):5b-9b.

52. Yarnell JW, Patterson CC, Sweetnam PM, et al. Do total and high density lipoprotein cholesterol and triglycerides act independently in the prediction of ischemic heart disease? Ten-year follow-up of Caerphilly and Speedwell Cohorts. Arterioscler Thromb Vasc Biol. 2001;21:1340-5.

53. Yu S, Yarnell JW, Sweetnam P, et al. High density lipoprotein subfractions and the risk of coronary heart disease: 9-years follow-up in the Caerphilly Study. Atherosclerosis. 2003;166:331-8.

54. Nordestgaard BG, Benn M, Schnohr P, et al. Nonfasting triglycerides and risk of myocardial infarction, ischemic heart disease, and death in men and women. JAMA. 2007;298:299-308.

55. Tirosh A, Rudich A, Shochat T, et al. Changes in triglyceride levels and risk for coronary heart disease in young men. Ann Intern Med. 2007;147:377-85.

56. Bansal S, Buring JE, Rifai N, et al. Fasting compared with nonfasting triglycerides and risk of cardiovascular events in women. JAMA. 2007;298:309-16.

57. Dunder K, Lind L, Zethelius B, et al. Evaluation of a scoring scheme, including proinsulin and the apolipoprotein $\mathrm{B}$ /apolipoprotein $\mathrm{A} 1$ ratio, for the risk of acute coronary events in middle-aged men: Uppsala Longitudinal Study of Adult Men (ULSAM). Am Heart $J$ 2004;148:596-601.

58. Sweetnam PM, Bolton CH, Downs LG, et al. Apolipoproteins A-I, A-II and B, lipoprotein(a) and the risk of ischaemic heart disease: the Caerphilly study. Eur J Clin Invest. 2000;30:947-56.

59. Despres JP, Lemieux I, Dagenais GR, et al. HDL-cholesterol as a marker of coronary heart disease risk: the Quebec cardiovascular study. Atherosclerosis. 2000;153:263-72.

60. Sarwar N, Danesh J, Eiriksdottir G, et al. Triglycerides and the risk of coronary heart disease: 10,158 incident cases among 262,525 participants in 29 Western prospective studies. Circulation. 2007;115:450-8.

61. Danesh J, Collins R, Appleby P, et al. Association of fibrinogen, C-reactive protein, albumin, or leukocyte count with coronary heart disease: meta-analyses of prospective studies. JAMA. 1998;279:1477-82.

62. Birjmohun RS, Hutten BA, Kastelein JJ, et al. Efficacy and safety of high-density lipoprotein cholesterol-increasing compounds: a meta-analysis of randomized controlled trials. J Am Coll Cardiol. 2005;45:185-97.
63. Edwards JE, Moore RA. Statins in hypercholesterolaemia: a dose-specific meta-analysis of lipid changes in randomised, double blind trials. BMC Fam Pract. 2003;4:18.

64. Law MR, Wald NJ, Rudnicka AR. Quantifying effect of statins on low density lipoprotein cholesterol, ischaemic heart disease, and stroke: systematic review and meta-analysis. BMJ. 2003;326:1423.

65. Davidson MH, McKenney JM, Shear CL, et al. Efficacy and safety of torcetrapib, a novel cholesteryl ester transfer protein inhibitor, in individuals with below-average high-density lipoprotein cholesterol levels. J Am Col Cardiol. 2006;48:1774-81.

66. Bays HE, McKenney JM, Dujovne CA, et al. Effectiveness and tolerability of a new lipid-altering agent, gemcabene, in patients with low levels of high-density lipoprotein cholesterol. Am J Cardiol. 2003;92:538-43.

67. Oram JF. Tangier disease and ABCA1. Biochim Biophys Acta. 2000;1529(1-3):321-30.

68. Benlian P, Etienne J, de Gennes JL, et al. Homozygous deletion of exon 9 causes lipoprotein lipase deficiency: possible intron-Alu recombination. J Lipid Res. 1995;36:356-66.

69. Benlian P, De Gennes JL, Foubert L, et al. Premature atherosclerosis in patients with familial chylomicronemia caused by mutations in the lipoprotein lipase gene. $N$ Engl J Med. 1996;335:848-54.

70. Hokanson JE. Functional variants in the lipoprotein lipase gene and risk cardiovascular disease. Curr Opin Lipidol. 1999;10:393-9.

71. Wittrup HH, Tybjaerg-Hansen A, Nordestgaard BG. Lipoprotein lipase mutations, plasma lipids and lipoproteins, and risk of ischemic heart disease. A meta-analysis. Circulation. 1999;99:2901-7.

72. Thorn JA, Needham EW, Mattu RK, et al. The Ser447-Ter mutation of the lipoprotein lipase gene relates to variability of serum lipid and lipoprotein levels in monozygotic twins. J Lipid Res. 1998;39:437-41.

73. Gagne SE, Larson MG, Pimstone SN, et al. A common truncation variant of lipoprotein lipase (Ser447X) confers protection against coronary heart disease: the Framingham Offspring Study. Clin Genet. 1999;55:450-4.

74. Breckenridge WC, Little JA, Alaupovic P, et al. Lipoprotein abnormalities associated with a familial deficiency of hepatic lipase. Atherosclerosis. 1982;45:161-79.

75. Hegele RA, Little JA, Vezina C, et al. Hepatic lipase deficiency. Clinical, biochemical, and molecular genetic characteristics. Arterioscler Thromb. 1993;13:720-8.

76. Ji J, Herbison CE, Mamotte CD, et al. Hepatic lipase gene - 514 C/T polymorphism and premature coronary heart disease. $J$ Cardiovasc Risk. 2002;9:105-13.

77. Hokanson JE, Kamboh MI, Scarboro S, et al. Effects of the hepatic lipase gene and physical activity on coronary heart disease risk. Am J Epidemiol. 2003;158:836-43.

78. Ruel IL, Couture P, Cohn JS, et al. Evidence that hepatic lipase deficiency in humans is not associated with proatherogenic changes in HDL composition and metabolism. J Lipid Res. 2004;45:1528-37. 
